\title{
Prólogo \\ Sociedad Civil y democracia en América Latina: desafíos de participación y representación
}

\author{
Antonio Elizalde Hevia
}

Email: antonio.elizalde@gmail.com

\section{Gonzalo Delamaza Escobar}

Email: gonzalo.delamaza@ulagos.cl

\section{María Gabriela Córdova Rivera}

Email: maria.cordova@ulagos.cl

¿Por qué plantearse los problemas de la sociedad civil desde el ángulo de la relación entre participación y representación? La elección del tema de este Lente de Aproximación responde a una visión tanto de los avances desarrollados por la investigación sobre sociedad civil en la región, como a un análisis de los procesos sociales y políticos más importantes que están verificándose en América Latina y el Caribe, de los cuales la sociedad civil forma parte y es a su vez condicionada por ellos.

Durante los años recientes la situación social y política en América Latina y el Caribe ha ido evolucionando de un modo extraordinariamente rápido. Del predominio neoliberal en los 90 y el confinamiento consecuente de la sociedad civil como auxiliar privado de los impactos del ajuste económico junto con el abandono de las funciones básicas del Estado, se ha pasado a la emergencia de variadas propuestas de cambio político y a un nuevo protagonismo de los actores y movimientos sociales que demandan soluciones a los urgentes problemas de la región. Crecimiento económico sostenido que contrasta con otras regiones del mundo, vigencia sostenida de los regímenes democráticos, cambios políticos hacia gobiernos de izquierda de variadas características, reformas constitucionales, son algunos de los fenómenos más resaltantes.

Al mismo tiempo se han consolidado y expandido las iniciativas del experimentalismo democrático regional, -del que hablan José Nun y Boaventura de Sousa Santos-, que buscan ampliar el espacio de las decisiones públicas. Así los presupuestos y la planeación participativos, los Consejos y Conferencias de Políticas Públicas con participación ciudadana, los programas de fortalecimiento y legislación (relativamente) favorables a la sociedad civil se multiplican en diversos países y varios de esos procesos tienen ya más de dos generaciones. 
También la movilización social masiva se ha intensificado, no sólo en la región sino en el mundo, a partir del año 2011, con actores nuevos (los jóvenes y estratos medios emergentes) y medios innovadores (las redes), con múltiples y heterogéneos objetivos, pero animados de un espíritu de transformación profundo, que se transmite de un país a otro, de una coyuntura a otra. Chile es un caso relevante de esta tendencia de la sociedad a expresarse con más fuerza y diversidad. No sólo acicateada por crisis económicas y las extremas desigualdades, sino en función de nuevos desafíos que vienen desde abajo: participación, descentralización, ampliación de las formas y mecanismos democráticos, tolerancia y no discriminación, interculturalidad, derechos y autonomía de los pueblos indígenas, cuestionamiento a los modelos de economía basados en la minería extractiva, concentradores y no sustentables, entre otros.

Estos y otros procesos entre ellos la crisis económica global, la pérdida de hegemonía de los bloques otrora dominantes, el vaciamiento de las organizaciones políticas tradicionales- han planteado nuevamente los desafíos de la representación democrática. La debilidad política histórica de nuestra región autoritarismo, populismo, clientelismo, dictaduras- se expresa hoy en la vigencia de la democracia en cuanto institucionalidad política (elecciones relativamente competitivas para conformar los órganos de poder), pero que aún no resuelve los problemas básicos de la activa inclusión de las mayorías en el proceso decisional. A pesar que desde la Constitución Ciudadana de Brasil en el 89 se vienen planteando modos de incorporación, renovación de los métodos de representación, pluralización del espacio político, etc. A ello se suma hoy día una pérdida de confianza en la institucionalidad democrática tradicional. No es un fenómeno puramente regional, pero adquiere aquí características propias y obliga a buscar respuestas.

Ni la participación ni la representación, los temas priorizados en este Lente de Aproximación, podrían ser resueltos desde fuera de la sociedad civil y sin su involucramiento. Antes bien forman parte de sus desafíos intrínsecos, en diálogo con las estructuras de poder. No podemos confiar en una suerte de magia política que los responda. Más bien el esfuerzo consiste en reflexionar acerca de cómo en la propia sociedad civil se incuban experiencias y respuestas que contribuyen al proceso social y político democratizador de la región. Por ello hemos planteado la discusión de nuevos paradigmas en torno a los procesos de participación y representación.

Aprovechando la oportunidad ofrecida por la IX Conferencia de la ISTR para América Latina y el Caribe en Santiago de Chile, dedicada a estos temas, en la sección Lente de Aproximación, entregamos a nuestros lectores un conjunto de nueve trabajos que abordan la problemática planteada con investigación empírica reciente realizada en diversos contextos y que ayudan a enriquecer la conceptualización sobre estos importantes problemas.

La insuficiencia de la forma de integración social conformada a par- 
tir de las reformas estructurales de matriz neoliberal se ha hecho evidente, incluso en aquellos países que parecían menos vulnerables a un cuestionamiento profundo del modelo. Ello ha abierto una ventana de oportunidad para la re-politización del espacio público y la redefinición del papel que las sociedades y sus organizaciones pueden jugar en este nuevo escenario. Pero ello implica desarrollar canales de participación para que sean los ciudadanos quienes definan las prioridades de su propio desarrollo, junto a reconstruir sistemas de representación consistentes con ello. La región experimenta hoy un giro político. Este giro ha sido señalado como la consolidación de políticas neo-populistas, estatistas y progresistas en parte importante de la región, sin embargo, sostener que el giro político se reduce a un giro en la tendencia política hegemónica, implica desconocer el antecedente lógico del giro, que no consiste primeramente en la izquierdización de la región, sino en la re-politización del espacio público y la sociedad.

La pregunta que surge es si están dadas las condiciones para que este escenario se traduzca efectivamente en una ampliación de la democracia y con nuevos y mejores canales de participación y representación política. El desafío que viven las sociedades latinoamericanas actualmente es el de construir una forma de articulación entre el Estado y la sociedad que no esté mediada por otra lógica ni por otras definiciones que aquellas que los propios sujetos decidan y sean capaces de llevar adelante, de allí la importancia de los temas que aborda este Lente de Aproximación.

Abre la sección, Evelyn Arriagada, quien presenta algunos de los resultados de la investigación realizada el 2009, en torno a liderazgos locales. Con su trabajo titulado Clientelismo político y participación local. El rol de los dirigentes sociales en la articulación entre autoridades y ciudadanos en Santiago de Chile, y desde un enfoque cualitativo, la autora analiza la construcción de vínculos políticos -y también su perdurabilidadentre alcalde y concejales, y bases sociales, en la comuna de Santiago.

Por su parte, Gabriela Cordioli Coto y Cristina Amélia Carvalho con su texto Limites e potencialidades da participação: a experiência do Programa Descentralização da Cultura de Porto Alegre, abordan la participación en la gestión municipal y su incidencia política. El mencionado Programa de Descentralización de la Cultura, no es sino el resultado de la lucha liderada por algunos grupos de la sociedad civil (en los 80 y 90) y su contribución a la radicalización democrática y la formación de nuevos valores y prácticas sociales, guiados por la ética colectiva.

A continuación, el trabajo de Gonzalo Delamaza Escobar De la elite civil a la elite política. Reproducción del poder en contextos de democratización, nos devuelve al contexto chileno, para analizar las trayectorias de las personas que, provenientes de la sociedad civil organizada, formaron parte de la elite política chilena entre 1990 y 2010. Entre los hallazgos, se postula que el amplio estamento de la sociedad civil chilena que accedió al poder político, pertenecía previamente a posiciones 
privilegiadas dentro de la misma, principalmente al segmento de mayor educación.

Rodrigo Flores, Darío Rodríguez, Paula Miranda y Camila Ramos realizan Un análisis cualitativo de los discursos de representantes de sindicatos, movimientos sociales y organizaciones no gubernamentales sobre el rol de las empresas y el Estado chileno que le da el nombre al artículo que nos presentan. Entre los resultados preliminares de su estudio, cabe mencionar el compartido descontento con: el funcionamiento de la institucionalidad económica y política chilena, el rol que de las empresas chilenas en el desarrollo de su responsabilidad social y el disminuido papel de Estado en la protección de derechos universales.

Desde otra perspectiva, Camila Jara Ibarra analiza la estructura socio-política de la redemocratización latinoamericana con su trabajo(Des) Movilización de la sociedad civil en América Latina: Factores tras las trayectorias de participación social. Tomando como eje central el impacto de las memorias colectivas, el paradigma de gobernabilidad democrático y la modernización neoliberal, el texto aborda las consecuencias de estos elementos para la acción social, la activación o efervescencia social en ciertos casos, o desactivación y desmovilización, en otros.

Desde la sociología cultural, Carlos Arturo Martínez Carmona, realiza un trabajo de campo con tres asociaciones de mujeres en Ciudad Juárez, cuyos principales resultados se plasman en su artículo Sociedad civil y exclusión en Ciudad Juárez. Consideraciones desde las asociaciones de mujeres. Mediante el análisis del discurso, se identifican las formas de exclusión de las mujeres respecto a la acción pública (lo profano) y así también, las formas de inclusión de éstas en la sociedad civil (lo sacro). Se constata que tanto el discurso basado en derechos, como la capacidad organizativa del movimiento, permiten dar luces de un panorama más inclusivo.

Desde el ámbito de la democracia participativa, Fabricio Pereira da Silva nos presenta Um olhar sobre as relações entre movimentos sociais e Estados refundados nos Países Andinos, a partir de teorias participativas da democracia. Desde un plano teórico, el artículo aborda los diferentes roles asumidos por los movimientos sociales en Venezuela, Bolivia y Ecuador, en la idea de buscar los puntos de referencia más adecuados para hacer frente a las concepciones de la democracia como la base de estos nuevos gobiernos y las instituciones de Estado rediseñados.

Por otro lado, Rubén Pino Ibáñez en su artículo Internet y capital social en localidades aisladas de Chile aborda la relación entre capital social, internet y geografía, mediante una metodología de estudio de casos en seis localidades de Chile con características de aislamiento, -en Aysén y Región Metropolitana-. Entre los principales resultados, se posiciona a internet como un medio eficiente para generar o bien mantener capital social. 
Cierra la sección Mauricio Rifo con Movimiento estudiantil, sistema educativo y crisis política actual. Su trabajo sitúa el debate en torno al actual movimiento estudiantil y su desenvolvimiento como apertura de enunciados políticos de transformación en relación a los nuevos escenarios político-sociales producidos por el neoliberalismo ya más consolidado.

La siguiente sección, Cartografías para el futuro, presenta únicamente un texto de homenaje a la figura y obra intelectual del sociólogo chileno Hugo Zemelman Merino, reconocido ampliamente en el contexto hispanoamericano por sus valiosos aportes en el plano epistemológico, quien fuera integrante del Comité Editorial de POLIS, Revista Latinoamericana, desde sus inicios. A cargo de Juan Pablo Paredes, el escrito lleva por título El Presente Potencial y la Conciencia Histórica: Realidad Social, Sujeto y Proyecto. A la memoria de Hugo Zemelman Merino.

En la sección Proyectos y Avances de Investigación se publica un total de once trabajos: (Des) Igualdad socio espacial y justicia espacial: nociones clave para una lectura crítica de la ciudad de Ana María Âlvarez Rojas; La cuestión de la colaboración intersectorial y de la integralidad de las políticas sociales: lecciones derivadas del caso del sistema de protección a la infancia en Chile de Nuria Cunill-Grau, Margarita Fernández A. y Marcel Thezá Manríquez; De caminatas a los juzgados: Análisis del discurso de los medios de prensa sobre el proyecto minero Crucitas de José Andrés Díaz González; El problema de la delimitación o boundary problem. Una aproximación a la definición de la clase media de Modesto Gayo; Sistemas de la violencia sociopolítica a cargo de Cruz García Lirios, Javier Carreón Guillén, Jorge Hernández Valdés y Agustín Méndez Martínez; Mercado y fe. Discusión entre Economía Ortodoxa y Teología de la Liberación. Lecturas de Franz Hinkelammert de Hugo Amador Herrera Torres, María Arcelia Gonzáles Butrón y José Antonio Toledo García; Contribuciones al estudio de Identidades e Identificaciones precarias en Chile de Dasten Julián Vejar; Genealogía de una vejez no anunciada: biopolítica de los cuerpos envejecidos o del advenimiento de la gerontogubernamentalidad de Mario Ociel Moya; La revitalización de la historiografía política chilena de José Ignacio Ponce López y Aníbal Pérez Contreras; Violencia del crimen organizado relacionada a los sectores económicos en México. Una propuesta de categorización de María Vanessa Romero Ortiz, Jorge Loza López y Felipe Machorro Ramos; y por último El Buen vivir: una utopía latinoamericana en el campo discursivo global de la sustentabilidad de Julien Vanhulst y Adrián E. Beling.

El número se cierra como habitualmente con la sección Reseñas y Comentarios de Libros que incluye las siguientes: de Fernando de la Cuadra sobre el libro Cambio climático, movimientos sociales y políticas públicas. Una vinculación necesaria de Julio Postigo (editor); de Geoffrey Durand sobre Memorias eclipsadas. Duelo y resiliencia comunitaria en la prisión política de Jorge Montealegre Iturra; de María Florencia Girola sobre el libro Construyendo barrios. Transformaciones socioterritoriales 
a partir de los Programas Federales de Vivienda en el Área Metropolitana de Buenos Aires (2004-2009) de María Cristina Cravino (org.); de Camila Ponce Lara sobre La démocratie Internet. Promesses et limites de Dominique Cardon ; y finalmente de Lorena Valdebenito Carrasco sobre El diablo en la música. La muerte del amor en El gavilán, de Violeta Parra de Lucy Oporto 